\title{
Can COVID-19 Cause Peripheral Facial Nerve Palsy?
}

\author{
Oguz Kadir Egilmez ${ }^{1}$ (D) $\cdot$ Mahmut Emre Gündoğan ${ }^{1} \cdot$ Mahmut Sinan Yılmaz ${ }^{1} \cdot$ Mehmet Güven ${ }^{1}$
}

Accepted: 18 May 2021 / Published online: 22 May 2021

(C) The Author(s), under exclusive licence to Springer Nature Switzerland AG 2021

\begin{abstract}
The aim of our study is to evaluate the relationship between peripheral facial paralysis and the patients who had a contact with a coronavirus disease 2019 (COVID-19) patient or had COVID-19. Patients with a history of contact with a COVID-19 patient or having COVID-19 disease, who were admitted to the emergency department for peripheral facial paralysis in the last 6 months, were included in the study. Facial paralysis grade at first presentation, treatment modality, treatment duration, post-treatment facial paralysis grade, and additional findings were analyzed. A total of 34 patients, 20 females and 14 males, were included into the study. Nasal-oropharyngeal reverse transcriptase-polymerase chain reaction (RT-PCR) was test taken from patients with a history of contact, and patients having COVID-19 disease were determined as positive in 5 and 3 patients, respectively. Peripheral facial paralysis was detected as an initial finding in 5 of these 8 patients, and paralysis developed in 7-12 days after the diagnosis of the COVID-19 disease in the remaining 3 patients. The grade of first admission paralysis did not change in one patient in the (+) group, while improvement was observed in all patients in the (-) group. Neuroinvasive potential of COVID-19 in the central and peripheral nervous system was reported in current literature. Our study indicates peripheral facial palsy can also be encountered during the clinical course of COVID-19 and should be considered a finding of this disease.
\end{abstract}

Keywords COVID-19 $\cdot$ Peripheral facial palsy $\cdot$ SARS-CoV-2

\section{Introduction}

The coronavirus disease 2019 (COVID-19), an emerging contagious disease that has caused an ongoing worldwide pandemic, continues with all its severity. Parallel to this, we are in the expanding stage of learning about this pandemic. Like other defined coronaviruses, COVID-19 primarily affects the upper and lower respiratory tract. After an incubation period, nonspecific findings like malaise, fever, and dry cough will appear [1]. Depending on the state of the patient's immune system and concomitant chronic diseases, the findings may remain mild or progress to a severe condition and even death [2-4]. Based on recently reported studies, COVID-19 can show neuro-invasive potential in the central and peripheral nervous system. Milder symptoms such as loss of taste and smell and headache were first reported [1]. But later, more

This article is part of the Topical Collection on COVID-19

Oguz Kadir Egilmez

oguzegilmez@gmail.com

1 Department of Otorhinolaryngology, Sakarya University Training and Research Hospital, Korucuk Campus, 54100 Sakarya, Turkey severe findings such as encephalitis, myelitis, cerebrovascular events, and even Guillain-Barré syndrome were also reported $[5,6]$.

Peripheral facial paralysis (PFP) is an otorhinolaryngologic emergency and is a disease that we frequently encounter in routine practice. Although the cause is not known exactly in all cases, it is thought to be caused by vascular ischemia, autoimmune diseases, or viral inflammation of the nerve sheath [7]. Among these reasons, viral inflammation is the most accepted, and the most commonly reported vectors are herpes simplex virus, as well as varicella zoster and human immunodeficiency viruses, Lyme disease, and Mycobacterium tuberculosis [8,9]. There are some wellknown non-infectious causes of PFP including trauma, sarcoidosis, and neoplasms [10]. The exact pathogenesis remains unclear, but in association with neurotropic viruses, it is assumed to be related to axonal transmission and viral reproduction causing inflammation and demyelination [11].

In the current literature, a few case reports of COVID-19related PFP and a case series of 8 patients with peripheral facial palsy related to COVID-19 have been reported [10, 12-14]. The aim of our study was to evaluate patients who applied to our clinic who had a history of COVID-19 disease or contact with COVID-19 patients and had peripheral facial 
paralysis during or after the active period of the disease or after the contact history and to examine the possible relationship between severe acute respiratory syndrome causing coronavirus-2 (SARS-CoV-2) and PFP.

\section{Methods}

Our study was initiated after it was approved by the Sakarya University Medical Faculty Local Ethics Committee (No: 01.12.2020/595). The files of patients who were seen for peripheral facial paralysis in the emergency department of our hospital between June 2020 and December 2020 were retrospectively reviewed. Patients with negative cytomegalovirus, Epstein-Barr virus, and herpes simplex virus serology, patients who were performed brain computed tomography (CT), diffusion, and brain magnetic resonance imaging (MRI) to exclude central nervous system vascular, tumoral, and infectious pathologies, and patients who were performed SARS-CoV-2 reverse transcriptase-polymerase chain reaction (RT-PCR) test at first admission were included in this study. Patients with any ear pathology (acute/chronic otitis media, etc.), a history of ear surgery or trauma, or peripheral facial paralysis caused by central pathologies diagnosed by brain CT or diffusion MRI taken in the emergency department were not included in the study. Recurrent PFP cases were also excluded.

Besides epidemiological information such as age and gender of the patients, RT-PCR results obtained at the time of admission, facial paralysis grade at first presentation, treatment modality (intratympanic/systemic/combined; intratympanic plus systemic steroid), treatment duration, post-treatment facial paralysis grade, and additional findings, imaging methods (thorax CT) and treatments for patients with COVID-19 RT-PCR test (+) were noted. Facial palsy was graded according to the House-Brackmann scale [15].

Data were analyzed by using the SPSS version 22.0 software program (Statistical Package for Social Sciences v.22, IBM, Chicago, IL). Descriptive statistics were done for the analysis.

\section{Results}

A total of 34 patients, 20 females and 14 males, who met the study criteria were included in the study. The mean age was $46.9 \pm 21.3$ years (minimum $4-$ maximum 90). A total of 31 patients had a history of contact with a COVID-19 patient, and 3 were COVID-19 RT-PCR (+) patients. Nasal-oropharyngeal RT-PCR test taken from patients with a history of contact was positive in 5 patients, and a total of 8 patients were evaluated as RT-PCR (+). Peripheral facial paralysis was detected as an initial finding in 5 of these 8 patients, and paralysis developed in 7-12 days after diagnosis of the COVID-19 disease in the other 3 patients.

Facial paralysis was detected in the right side of the face in 15 patients, 2 of whom were in the RT-PCR (+) group, and paralysis was detected on the left side in 19 patients, 6 of them in the (+) group. At first admission, 3 of the RT-PCR (+) patients had grade (3) and 5 had grade (4) palsy, while in the RT-PCR (-) group, grade (2) was detected in 3 patients, grade (3) in 10 , grade (4) in 9, grade (5) in 3, and grade (6) palsy was detected in 1 patient (Table 1 ).

All patients, in addition to eye-sparing treatment, according to the level of their chronic diseases (additional comorbid diseases - diabetes mellitus type II, essential hypertension, congestive heart failure, and obstructive sleep apnea syndrome (OSAS) - were detected in 4 patients), were treated with steroids as follows:

* Systemic $(1 \mathrm{mg} / \mathrm{kg}$ methylprednisolone oral; 1 in 3 days, with dose reduction; for 2 weeks) in patients having no comorbid diseases

* Intratympanic (ITS) (8 mg/2 ml dexamethasone; 1 in 2 days; 6 doses) in patients having comorbid diseases

* Combined in patients who did not benefit from systemic treatment

ITS was applied to 3 patients, systemic therapy to 4, and combined therapy to 1 of the RT-PCR (+) patients. The treatment lasted for 2 weeks in 5 and 4 weeks in 3 patients. In the RT-PCR (-) group, ITS was applied in 9 patients, systemic in 13 patients, and combined therapy in 4 patients. The treatment lasted 2 weeks for 20 patients and 4 weeks for 6 patients. The grade of first admission paralysis did not change in one patient in the $(+)$ group, while improvement was observed in all patients in the $(-)$ group (Table 1).

One of the RT-PCR (+) patients was hospitalized and died due to severe pneumonia. The other 7 patients were treated on an outpatient basis. Five of the outpatients received favipiravir for 5-10 days in addition to steroid therapy. In addition, loss of taste and smell was reported in six patients. Otalgia was also detected in one patient (Table 2).

In the thoracic CT of (+) patients, intense pneumonia (the patient who died) was found in one patient, mild pneumonia was found in 3 patients, but no additional findings were found in brain CT, diffusion MRI, and inner ear MRI images (Table 2).

\section{Discussion}

Bell's palsy is a type of sudden onset, one-sided facial paralysis designated with lower motor neuron dysfunction of the 7 th cranial nerve [16]. It affects the entire 
Table 1 Epidemiological information and clinical manifestations of patients with peripheral facial paralysis admitted to ENT clinic

\begin{tabular}{|c|c|c|c|c|c|c|c|c|}
\hline $\begin{array}{l}\text { Patient } \\
\text { no. }\end{array}$ & PCR & Age & Gender & $\begin{array}{l}\text { Side of } \\
\text { palsy }\end{array}$ & $\begin{array}{l}\text { Grade at first } \\
\text { admission }\end{array}$ & $\begin{array}{l}\text { Treatment } \\
\text { type }\end{array}$ & $\begin{array}{l}\text { Treatment } \\
\text { duration }\end{array}$ & $\begin{array}{l}\text { Grade after } \\
\text { treatment }\end{array}$ \\
\hline 1 & Negative & 48 & $\mathrm{~F}$ & Left & 3 & ITS & 2 weeks & 1 \\
\hline 2 & Negative & 14 & M & Left & 5 & Systemic & 2 weeks & 1 \\
\hline 3 & Negative & 74 & M & Right & 3 & ITS & 2 weeks & 2 \\
\hline 4 & Negative & 47 & $\mathrm{~F}$ & Left & 4 & ITS & 2 weeks & 2 \\
\hline 5 & Negative & 73 & $\mathrm{~F}$ & Right & 5 & ITS & 2 weeks & 2 \\
\hline 6 & Negative & 24 & M & Right & 4 & Systemic & 2 weeks & 1 \\
\hline 7 & Negative & 55 & $\mathrm{~F}$ & Right & 2 & Systemic & 2 weeks & 1 \\
\hline 8 & Negative & 29 & M & Left & 3 & Combined & 4 weeks & 2 \\
\hline 9 & Negative & 60 & M & Left & 2 & Systemic & 2 weeks & 1 \\
\hline 10 & Negative & 35 & M & Right & 4 & Combined & 4 weeks & 2 \\
\hline 11 & Negative & 19 & $\mathrm{~F}$ & Right & 6 & Combined & 4 weeks & 3 \\
\hline 12 & Negative & 71 & $\mathrm{~F}$ & Left & 3 & Systemic & 2 weeks & 1 \\
\hline 13 & Negative & 45 & M & Right & 3 & ITS & 2 weeks & 1 \\
\hline 14 & Negative & 69 & $\mathrm{~F}$ & Left & 4 & ITS & 4 weeks & 3 \\
\hline 15 & Negative & 22 & $\mathrm{~F}$ & Left & 3 & Systemic & 2 weeks & 1 \\
\hline 16 & Negative & 30 & $\mathrm{~F}$ & Right & 3 & Combined & 4 weeks & 2 \\
\hline 17 & Negative & 57 & $\mathrm{~F}$ & Right & 4 & Systemic & 2 weeks & 2 \\
\hline 18 & Negative & 59 & $\mathrm{~F}$ & Left & 2 & Systemic & 2 weeks & 1 \\
\hline 19 & Negative & 28 & M & Left & 4 & Systemic & 2 weeks & 1 \\
\hline 20 & Negative & 49 & M & Right & 4 & Systemic & 2 weeks & 2 \\
\hline 21 & Negative & 59 & $\mathrm{~F}$ & Right & 5 & ITS & 4 weeks & 3 \\
\hline 22 & Negative & 42 & $\mathrm{~F}$ & Right & 4 & ITS & 2 weeks & 2 \\
\hline 23 & Negative & 34 & $\mathrm{M}$ & Left & 3 & Systemic & 2 weeks & 1 \\
\hline 24 & Negative & 72 & M & Right & 3 & ITS & 2 weeks & 2 \\
\hline 25 & Negative & 49 & $\mathrm{~F}$ & Left & 3 & Systemic & 2 weeks & 1 \\
\hline 26 & Negative & 32 & M & Left & 4 & Systemic & 2 weeks & 1 \\
\hline 27 & Positive & 90 & M & Left & 4 & ITS & 2 weeks & 2 \\
\hline 28 & Positive & 4 & $\mathrm{~F}$ & Left & 4 & Systemic & 2 weeks & 1 \\
\hline 29 & Positive & 17 & $\mathrm{~F}$ & Right & 3 & Combined & 4 weeks & 1 \\
\hline 30 & Positive & 71 & $\mathrm{~F}$ & Right & 4 & ITS & 2 weeks & 1 \\
\hline 31 & Positive & 63 & $\mathrm{~F}$ & Left & 4 & Systemic & 4 weeks & 2 \\
\hline 32 & Positive & 60 & $\mathrm{~F}$ & Left & 4 & Systemic & 2 weeks & 2 \\
\hline 33 & Positive & 65 & $\mathrm{~F}$ & Left & 3 & ITS & 2 weeks & 2 \\
\hline 34 & Positive & 30 & M & Left & 3 & Systemic & 4 weeks & 3 \\
\hline
\end{tabular}

$E N T$ ear-nose-throat; $M$ male; $F$ female; $P C R$ SarS-CoV-2 reverse transcriptase polymerase chain reaction test; ITS intratympanic steroid; Grade House-Brackmann grading scale population, regardless of age or gender, and from many populations, the incidence has been reported as 11.5-53.3 per 100,000 persons [16]. The most widely accepted causes for Bell's palsy are inflammatory, traumatic, and infectious processes [7]. Although there is a certain link between viral infection and Bell's palsy, this is frequently associated with members of the Herpesviridae [12]. Studies have reported that HSV-1 DNA was detected around the geniculate nucleus and in the endoneurial fluid of the facial nerve in patients with Bell's palsy $[17,18]$. Particularly, HSV and VZV infections are most prominently determined, but many vectors that can cause Bell's palsy have been identified. These are Epstein-Barr virus, human herpesvirus 6 (HHV-6), human immunodeficiency virus (HIV), hepatitis B, influenza, adenovirus, rubella, mumps, and coxsackievirus, as well as Lyme disease and Mycobacterium tuberculosis [10, 19-24]. Sarcoidosis and neoplasms can also be considered in the non-infectious group [10]. The exact pathogenesis of acute-onset facial nerve paralysis is not known exactly, but in association with neurotropic herpes viruses (HSV and VZV), it is thought to be associated with axonal 
Table 2 Additional findings of COVID-19 PCR (+) patients

\begin{tabular}{|c|c|c|c|c|c|c|}
\hline $\begin{array}{l}\text { Patient } \\
\text { no. }\end{array}$ & COVID-19 findings & Thorax CT & $\begin{array}{l}\text { First } \\
\text { symptom }\end{array}$ & Additional imaging & Additional treatment & $\begin{array}{l}\text { Comorbid } \\
\text { disease }\end{array}$ \\
\hline 27 & $\begin{array}{l}\text { Severe pneumonia, } \\
\text { hospitalization, died }\end{array}$ & $\begin{array}{l}\text { Intense } \\
\quad \text { pneumo- } \\
\text { nia }\end{array}$ & Yes & Normal brain $\mathrm{CT}+$ diffusion MRI & $\begin{array}{l}\text { IV moxifloxacin + IV } \\
\text { prendnisolone }\end{array}$ & $\mathrm{HT}, \mathrm{CHF}$ \\
\hline 28 & Cough, fever & Normal & $\begin{array}{c}\text { No (after } 7 \\
\text { days) }\end{array}$ & Normal brain CT + diffusion MRI & No & No \\
\hline 29 & Cough, loss of taste/smell & Normal & Yes & Normal brain $\mathrm{CT}$ & Favipravir 5 days & No \\
\hline 30 & Fever, loss of taste/smell & Normal & Yes & Normal brain CT + diffusion MRI & Favipravir 5 days & HT, DM \\
\hline 31 & $\begin{array}{l}\text { Fever, myalgia, loss of } \\
\text { taste/smell }\end{array}$ & $\begin{array}{l}\text { Mild } \\
\text { pneumo- } \\
\text { nia }\end{array}$ & Yes & $\begin{array}{l}\text { Normal brain } \mathrm{CT}+\text { diffusion MRI + } \\
\text { inner ear MRI }\end{array}$ & Favipravir 5 days & No \\
\hline 32 & Fever, loss of taste/smell & Normal & $\begin{array}{c}\text { No (after } 12 \\
\text { days) }\end{array}$ & Normal brain $\mathrm{CT}+$ diffusion MRI & Favipravir 7 days & No \\
\hline 33 & Loss of taste/smell & $\begin{array}{l}\text { Mild } \\
\text { pneumo- } \\
\text { nia }\end{array}$ & Yes & Normal brain $\mathrm{CT}+$ diffusion MRI & No & HT \\
\hline 34 & Otalgia, loss of taste/smell & $\begin{array}{l}\text { Mild } \\
\text { pneumo- } \\
\text { nia }\end{array}$ & $\begin{array}{c}\text { No (after } 9 \\
\text { days) }\end{array}$ & $\begin{array}{l}\text { Normal brain CT + diffusion MRI + } \\
\text { inner ear MRI }\end{array}$ & Favipravir 10 days & HT, OSAS \\
\hline
\end{tabular}

COVID-19 coronavirus disease 2019; PCR SarS-CoV-2 reverse transcriptase polymerase chain reaction test; $C T$ computed tomography; $M R I$ magnetic resonance imaging; $I V$ intravenous; $H T$ hypertension; $C H F$ congestive heart failure; $D M$ diabetes mellitus; OSAS obstructive sleep apnea syndrome

spread and viral replication, which leads to inflammation and demyelination in the nerve [11].

In idiopathic facial nerve paralysis, ischemia of vasa nervorum and demyelination induced by an inflammatory process can be supposed as possible mechanisms related to nerve damage [16]. In several postmortem studies, vascular changes and related microthrombi have been consistently reported [25]. As is known, hypercoagulability occurs in some patients with COVID-19 disease, which can result in vascular endothelial damage and related arterial and venous thrombotic complications [26]. This situation appears as a finding that supports the pathogenesis of facial paralysis. Direct viral damage or an autoimmune reaction producing inflammation toward the nerve would be alternative or contributing mechanisms to dysfunction. Increased deterioration of nerve functions can occur with direct viral damage or an autoimmune event that can trigger a boost in inflammation of the nerve [14].

According to recently reported studies, there is increasing information suggesting a neuroinvasive capacity of COVID19 [27]. SARS-CoV-2 is identical in infectious mechanism to other common coronaviruses $(\mathrm{CoV})$. Neuro-invasive propensity is one of the important features of $\mathrm{CoV}$, and so SARSCoV-2 is likely to have neurotrophic activities as well [13, 27]. Since this virus has a high affinity for ACE- 2 receptors, which are frequently found in the nervous system, it performs neurotropism by directly causing nerve damage [27-29]. The ACE2 receptor is highly expressed in ciliated epithelium and goblet cells, with viral replication being highest in the nasal mucosa, as can be understood from the detection of high viral load by examining nasal cells [30]. SARS-CoV-2 can reach the central nervous system through the olfactory nerve and bulb, which can be directly opened to the central nervous system, or through viremia. A limited number of studies related to neurological complications of COVID-19 have been reported up to now in the literature. Mao et al. reported a study on the neurological manifestations of COVID-19 patients. Their findings showed that headache was among the central findings and hyposmia was of the most encountered peripheral nervous system findings. In that study, $36.4 \%$ of COVID19 patients complained of neurological symptoms [31]. In a study by Korkmaz et al., otolaryngological manifestations were examined in COVID-19 patients and a considerable number of neurological findings, such as vertigo/dizziness, headache, and loss of taste and smell, were also mentioned as common symptoms in COVID-19 patients [32]. In milder cases, peripheral nervous system manifestations were predominant, including not only taste and smell disorders but also Guillain-Barré and Miller-Fisher syndromes [33-35]. In the majority of patients with severe COVID-19, encephalopathy, cerebrovascular complications, and myelitis were reported as other neurological complications $[5,6]$.

In our study, 34 patients were evaluated and 8 of them were evaluated as COVID-19 RT-PCR (+). Peripheral facial paralysis was the first finding in 5 of these 8 patients, and the RTPCR test performed at the time of first admission was found to be (+), suggesting that peripheral facial palsy could be a sole symptom in COVID-19. In a series of 8 cases reported by Lima et al., peripheral facial paralysis was reported as the first 
symptom in 3 patients included in the study [14]. Similar to our study, although female patients were more common, it is difficult to make a definite assessment that it can be seen more frequently in women due to the small number of cases. Similarly, the facial paralysis severity of the patients with positive SARS-CoV-2 virus was less severe, but in one of the patients we included in our study, no improvement was achieved in the palsy grade despite 1 month of steroid treatment. This patient was obese and had hypertension and OSAS as comorbidities. We thought that these comorbid diseases and high weight and also the effect of COVID-19 may predispose to hypercoagulopathy, and can cause not complete recovery and decrease the effectiveness of the steroid treatment. However, in the study of Lima et al., it was reported that most of the patients fully recovered [14]. The rate of complete recovery was lower in our study group (37.5\%). The serology of herpesvirus, Epstein-Barr virus, and cytomegalovirus, which are the most common viral agents in patients with facial paralysis, should be checked at the first application for diagnosis and treatment plan. Again, in patients presenting with facial paralysis, imaging methods and even cerebrospinal fluid (CSF) examination with lumbar puncture (LP) may be required to exclude pathologies affecting the central nervous system. The patients we included in our study were serologically examined and found negative, and also patients who did not have a pathology affecting the central nervous system in imaging methods were included. Since there are no symptoms observed when the CNS is affected, such as neck stiffness and confusion, the need for LP was not considered and performed in these patients. In the study of Lima et al., CSF examination was performed with LP in 6 of 8 patients and results were found to be normal except for a slight protein increase in only one patient [14]. Steroid (systemic-intratympanic-combined) and antiviral treatments (if viral agents are detected) are oftenly used in the treatment of facial paralysis. The patients in our study were also treated with steroids and it was deemed appropriate to give favipiravir treatment to 5 of (+) 8 patients. Favipiravir is a pyrazinecarboxamide derivative with activity against RNA viruses. It was initially approved for therapeutic use in resistant cases of influenza. In our country, in the COVID-19 treatment guideline, this drug is used for patients diagnosed with the disease in the first week to benefit from its antiviral effectiveness. Despite favipravir in one of the 5 patients in our study, no improvement in facial paralysis was observed, who was the patient with HT and OSAS. There are also case reports in the literature suggesting that the SARS-CoV-2 virus may cause peripheral facial paralysis. One of the reports is a 6-year-old male patient reported by Theophanous et al. [12]. Another case is a pregnant patient reported by Figueiredo et al. [13]. Ribeiro and Marchiori also reported a 26-year-old male patient [36]. Goh et al. presented a case of peripheral facial paralysis that developed on the sixth day of COVID-19 disease in a 27-year-old male patient [10].
Muras et al. also reported a patient with bilateral facial palsy who presented evidence of SARS-CoV-2 infection and coinfection with Epstein-Barr virus [37]. Zammit et al. and Codeluppi et al. reported that SARS-CoV-2 increased the incidence of peripheral facial paralysis by comparing a certain period of the COVID-19 pandemic with previous years in terms of incidence and emphasized the first presentation symptom of COVID-19 patients may be facial paralysis [38, 39]. In addition to these cases and case series reported in the literature, our study shows that there may be a strong relationship between COVID-19 and peripheral facial paralysis.

Some types of vaccines have been developed over the past year to slow down or even end the COVID-19 pandemic. The US Food and Drug Administration (FDA) has approved vaccines developed with mRNA technology and vaccination studies have been initiated. However, in the vaccinated groups during phase III studies, it was reported that 3 out of 15,185 volunteers in one group and 4 out of 18,801 volunteers in the other group developed peripheral facial paralysis after vaccination. It has been reported that there is no significant difference compared to the total population incidence, and vaccination and facial paralysis cannot be associated at this stage (https://www.entnet.org/content/covid-19-resource-page). However, even this situation raises the suspicion that peripheral facial paralysis may be associated with SARSCoV-2.

\section{Conclusions}

In conclusion, progression of the COVID-19 pandemic is leading to a growing number of neurological symptoms and syndromes. The COVID-19 agent, the SARS-CoV-2 virus, can have an effect on facial nerve functions by direct toxic effect to the nerve or by increasing hypercoagulopathy. Supporting this, our study showed that peripheral facial palsy can be encountered during the clinical course of COVID-19 and be considered a sole finding of this disease, along with the most common symptoms (such as fever, cough, and respiratory symptoms). Neurological symptoms could be significant early findings of COVID-19. Therefore, it should be kept in mind that COVID-19 may be a potential cause of peripheral facial paralysis.

\footnotetext{
Author Contribution Conceptualization: Oguz Kadir Egilmez, Mahmut Emre Gündogan

Data curation: Oguz Kadir Egilmez, Mahmut Emre Gündogan Formal analysis: Oguz Kadir Egilmez, Mahmut Emre Gündogan, Mahmut Sinan Yilmaz, Mehmet Guven

Methodology: Oguz Kadir Egilmez, Mahmut Sinan Yilmaz

Project administration: Mahmut Sinan Yilmaz, Mehmet Guven

Writing-original draft: Oguz Kadir Egilmez, Mahmut Emre Gündogan, Mahmut Sinan Yilmaz, Mehmet Guven
} 
Writing — review and editing: Oguz Kadir Egilmez, Mahmut Emre Gündogan, Mahmut Sinan Yilmaz, Mehmet Guven

Availability of Data and Material It can be provided if desired.

Code Availability Not applicable.

\section{Declarations}

Ethical Approval All procedures performed in studies involving human participants were in accordance with the ethical standards of the institutional and/or national research committee and with the 1964 Helsinki Declaration and its later amendments or comparable ethical standards. The study was approved by Institutional Review Board of the Sakarya University Board of Ethics (No: 12.01.2020/595).

Consent to Participate Not applicable.

Consent for Publication Not applicable.

Conflict of Interest The authors declare no competing interests.

\section{References}

1. Paybast S, Gorji R, Mavandadi S. Guillain-Barré syndrome as a neurological complication of novel COVID-19 infection: a case report and review of the literature. Neurologist. 2020;25:101-3. https://doi.org/10.1097/NRL.0000000000000291.

2. Huang C, Wang Y, Li X, Ren L, Zhao J, Hu Y, et al. Clinical features of patients infected with 2019 novel coronavirus in Wuhan, China. Lancet. 2020;395:497-506.

3. Chen N, Zhou M, Dong X, Qu J, Gong F, Han Y, et al. Epidemiological and clinical characteristics of 99 cases of 2019 novel coronavirus pneumonia in Wuhan, China: a descriptive study. Lancet. 2020;395:507-13.

4. Zhu N, Zhang D, Wang W, Li X, Yang B, Song J, et al. A novel coronavirus from patients with pneumonia in China, 2019. N Engl J Med. 2020;382:727-33.

5. Ellul MA, Benjamin L, Singh B, Lant S, Michael BD, Easton A, et al. Neurological associations of COVID-19. Lancet Neurol. 2020;19:767-83. https://doi.org/10.1016/S1474-4422(20)30221-0.

6. Paterson RW, Brown RL, Benjamin L, Nortley R, Wiethoff S, Bharucha $\mathrm{T}$, et al. The emerging spectrum of COVID-19 neurology: clinical, radiological and laboratory findings. Brain. 2020;143: 3104-20. https://doi.org/10.1093/brain/awaa240.

7. May M, Klein SR. Differential diagnosis of facial nerve palsy. Otolaryngol Clin N Am. 1991;24:613-45.

8. Bayindir T, Tan M, Selimoglu E. Diagnosis and management of bell palsy. KBB-Forum. 2011;10:18-30.

9. Owusu JA, Stewart CM, Boahene K. Facial nerve paralysis. Med Clin North Am. 2018;102:1135-43. https://doi.org/10.1016/j. mona.2018.06.011.

10. Goh Y, Beh DLL, Makmur A, Somani J, Chan ACY. Pearls \& Oysters: facial nerve palsy in COVID-19 infection. Neurology. $2020 ; 95: 364-7$. https://doi.org/10.1212/WNL. 0000000000009863 .

11. Eviston TJ, Croxson GR, Kennedy PG, Hadlock T, Krishnan AV. Bell's palsy: aetiology, clinical features and multidisciplinary care. J Neurol Neurosurg Psychiatry. 2015;86:1356-61. https://doi.org/ 10.1136/jnnp-2014-309563.
12. Theophanous C, Santoro JD, Itani R. Bell's palsy in a pediatric patient with hyper IgM syndrome and severe acute respiratory syndrome coronavirus 2 (SARS-CoV-2). Brain and Development. 2021;43:357-9. https://doi.org/10.1016/j.braindev.2020.08.017.

13. Figueiredo R, Falcão V, Pinto MJ, Ramalho C. Peripheral facial paralysis as presenting symptom of COVID-19 in a pregnant woman. BMJ Case Rep. 2020;13:e237146. https://doi.org/10.1136/bcr2020-237146.

14. Lima MA, Silva MTT, Soares CN, Coutinho R, Oliveira HS, Afonso L, et al. Peripheral facial nerve palsy associated with COVID-19. J Neurovirol. 2020;26:941-4. https://doi.org/10.1007/ s13365-020-00912-6.

15. House JW, Brackmann DE. Facial nerve grading system. Otolaryngol Head Neck Surg. 1985;93:146-7. https://doi.org/10. 1177/019459988509300202.

16. Zhang W, Xu L, Luo T, Wu F, Zhao B, Li X. The etiology of Bell's palsy: a review. J Neurol. 2020;267:1896-905. https://doi.org/10. 1007/s00415-019-09282-4.

17. Murakami S, Mizobuchi M, Nakashiro Y, Doi T, Hato N, Yanagihara N. Bell palsy and herpes simplex virus: identification of viral DNA in endoneurial fluid and muscle. Ann Intern Med. 1996;124(1 Pt 1):27-30. https://doi.org/10.7326/0003-4819-1241 part 1-199601010-00005.

18. McCormick DP. Herpes simplex virus as a cause of Bell's palsy. 1972. Rev Med Virol. 2000;10:285-9. https://doi.org/10.1002/ 1099-1654(200009/10)10:5<285::aid-rmv269>3.0.co;2-h.

19. Grose C, Henle W, Henle G, Feorino PM. Primary Epstein-Barrvirus infections in acute neurologic diseases. $\mathrm{N}$ Engl $\mathrm{J}$ Med. $1975 ; 292: 392-5$. https://doi.org/10.1056/ NEJM197502202920804.

20. Shaw FE Jr, Graham DJ, Guess HA, Milstien JB, Johnson JM, Schatz GC, et al. Postmarketing surveillance for neurologic adverse events reported after hepatitis B vaccination. Experience of the first three years. Am J Epidemiol. 1988;127:337-52. https://doi.org/10. 1093/oxfordjournals.aje.a114808.

21. Bélec L, Gherardi R, Georges AJ, Schüller E, Vuillecard E, Di Costanzo B, et al. Peripheral facial paralysis and HIV infection: report of four African cases and review of the literature. J Neurol. 1989;236:411-4. https://doi.org/10.1007/BF00314900.

22. Balatsouras DG, Kaberos A, Korres S, Leontiadis A, Kandiloros D. Infectious causes of bilateral facial nerve palsy. J Otolaryngol. 2007:36:E42-4. https://doi.org/10.2310/7070.0124.

23. Pitkäranta A, Piiparinen H, Mannonen L, Vesaluoma M, Vaheri A. Detection of human herpesvirus 6 and varicella-zoster virus in tear fluid of patients with Bell's palsy by PCR. J Clin Microbiol. 2000;38:2753-5. https://doi.org/10.1128/JCM.38.7.2753-2755. 2000.

24. Wijnans L, Dodd CN, Weibel D, Sturkenboom M. Bell's palsy and influenza(H1N1)pdm09 containing vaccines: a self-controlled case series. PLoS One. 2017;12:e0175539. https://doi.org/10.1371/ journal.pone.0175539.

25. Duarte-Neto AN, Monteiro RAA, da Silva LFF, Malheiros DMAC, de Oliveira EP, Theodoro-Filho J, et al. Pulmonary and systemic involvement in COVID-19 patients assessed with ultrasoundguided minimally invasive autopsy. Histopathology. 2020;77: 186-97. https://doi.org/10.1111/his.14160.

26. Bílková S, Hirmerová J. Coagulopathy associated with COVID-19. Vnitr Lek. 2020;66:402-8 English.

27. Li YC, Bai WZ, Hashikawa T. The neuroinvasive potential of SARS-CoV2 may play a role in the respiratory failure of COVID19 patients. J Med Virol. 2020;92:552-5. https://doi.org/10.1002/ jmv. 25728 .

28. Wrapp D, Wang N, Corbett KS, Goldsmith JA, Hsieh CL, Abiona O, et al. Cryo-EM structure of the 2019-nCoV spike in the prefusion conformation. Science. 2020;367:1260-3. https://doi. org/10.1126/science.abb2507. 
29. Walls AC, Park YJ, Tortorici MA, Wall A, McGuire AT, Veesler D. Structure, function, and antigenicity of the SARS-CoV-2 spike glycoprotein. Cell. 2020;181:281-92.e6. https://doi.org/10.1016/j. cell.2020.02.058.

30. Speth MM, Singer-Cornelius T, Oberle M, Gengler I, Brockmeier SJ, Sedaghat AR. Olfactory dysfunction and sinonasal symptomatology in COVID-19: prevalence, severity, timing, and associated characteristics. Otolaryngol Head Neck Surg. 2020;163:114-20. https://doi.org/10.1177/0194599820929185.

31. Mao L, Jin H, Wang M, Hu Y, Chen S, He Q, et al. Neurologic manifestations of hospitalized patients with coronavirus disease 2019 in Wuhan, China. JAMA Neurol. 2020;77:683-90. https:// doi.org/10.1001/jamaneurol.2020.1127.

32. Özçelik Korkmaz M, Eğilmez OK, Özçelik MA, Güven M. Otolaryngological manifestations of hospitalised patients with confirmed COVID-19 infection. Eur Arch Otorhinolaryngol. 2020:111. https://doi.org/10.1007/s00405-020-06396-8.

33. Brisca G, Garbarino F, Carta S, Palmieri A, Vandone M, Severino $\mathrm{M}$, et al. Increased childhood peripheral facial palsy in the emergency department during COVID-19 pandemic. Pediatr Emerg Care. 2020;36:e595-6. https://doi.org/10.1097/PEC. 0000000000002231 .

34. Toscano G, Palmerini F, Ravaglia S, Ruiz L, Invernizzi P, Cuzzoni MG, et al. Guillain-Barré syndrome associated with SARS-CoV-2.
N Engl J Med. 2020;382:2574-6. https://doi.org/10.1056/ NEJMc2009191.

35. Gutiérrez-Ortiz C, Méndez-Guerrero A, Rodrigo-Rey S, San PedroMurillo E, Bermejo-Guerrero L, Gordo-Mañas R, et al. Miller Fisher syndrome and polyneuritis cranialis in COVID-19. Neurology. 2020;95:e601-5. https://doi.org/10.1212/WNL. 0000000000009619.

36. Ribeiro BNF, Marchiori E. Facial palsy as a neurological complication of SARS-CoV-2. Arq Neuropsiquiatr. 2020;78:667. https:// doi.org/10.1590/0004-282X20200127.

37. Cabrera Muras A, Carmona-Abellán MM, Collía Fernández A, Uterga Valiente JM, Antón Méndez L, García-Moncó JC. Bilateral facial nerve palsy associated with COVID-19 and Epstein-Barr virus co-infection. Eur J Neurol. 2021;28:358-60. https://doi.org/10.1111/ene.14561.

38. Zammit M, Markey A, Webb C. A rise in facial nerve palsies during the coronavirus disease 2019 pandemic. J Laryngol Otol. 2020:1-4. https://doi.org/10.1017/S0022215120002121.

39. Codeluppi L, Venturelli F, Rossi J, Fasano A, Toschi G, Pacillo F, et al. Facial palsy during the COVID-19 pandemic. Brain Behav. 2020:e01939. https://doi.org/10.1002/brb3.1939.

Publisher's Note Springer Nature remains neutral with regard to jurisdictional claims in published maps and institutional affiliations. 